Vol.17, No. 62, January, 2022, 355-366

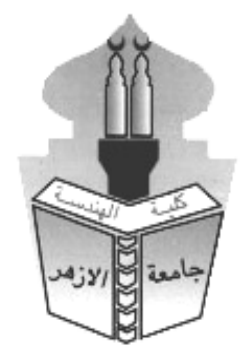

\title{
COMPATIBILITY BETWEEN SPATIAL FUNCTIONALITIES RELATED TO TRADE WITH THE LAST ADMINISTRATIVE ORGANIZATION OF TÉBESSA STATE-ALGERIA
}

\author{
Fahmi Toumi ${ }^{1 *}$ Djamel Alkama ${ }^{2}$ \\ ${ }^{1}$ Urbain Techniques Management Institute, Larbi Ben M'hidi University, Oum El Bouaghi, Algeria \\ ${ }^{2}$ Department of Architecture, faculty of science and technology, 08 May 1945 University, Guelma, Algeria \\ *Corresponding Author E-mail: fahmitoumi@univ-oeb.dz
}

Received :18 Octt. $2021 \quad$ Accepted:10 Nov. 2021

\begin{abstract}
This research is to clarify the long compatibility of commercial structure for cities of state of Tebessa along with its last administration organization, which it contains the presidential decree 19-328 dated in 8 December 2019 which complete the presidential decree 15-140 dated in 27 th may 2015 which contained create administration districts in some state .

And this study applied the commercial stores which was counted in place within the period between 2017 and 2020 into a lot of tests along space and statistics laws to approve on the compatibility of commercial structure like functional layer with administration decision obligation related to administration organization for the state.

In this research, the compatibility between the commercial structure and the levels of administrative organization at the seat of the State and at the seat of the administrative aspects, and its imbalance at the level of the seat of the departments and the municipals, was demonstrated.
\end{abstract}

Keywords: Commercial Structure, Administration Organization, Compatibility. State of Tebessa

$$
\begin{aligned}
& \text { التوافق بين الوظيفية المكاية المرتبطة بالمحلات التجارية والتقسيم الإداري الأخير بولاية تبسة ــ الجزائر - }
\end{aligned}
$$

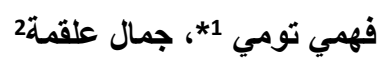

$$
\begin{aligned}
& \text { معهد تسيير التقنيات الحضرية, جامعة العربي بن مهيدي, أم البواقي, الجزائر. }
\end{aligned}
$$

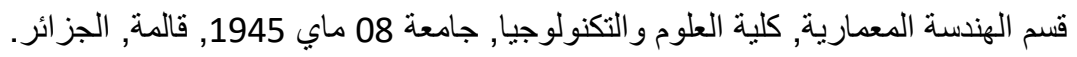

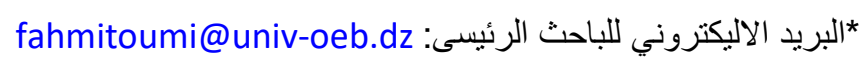




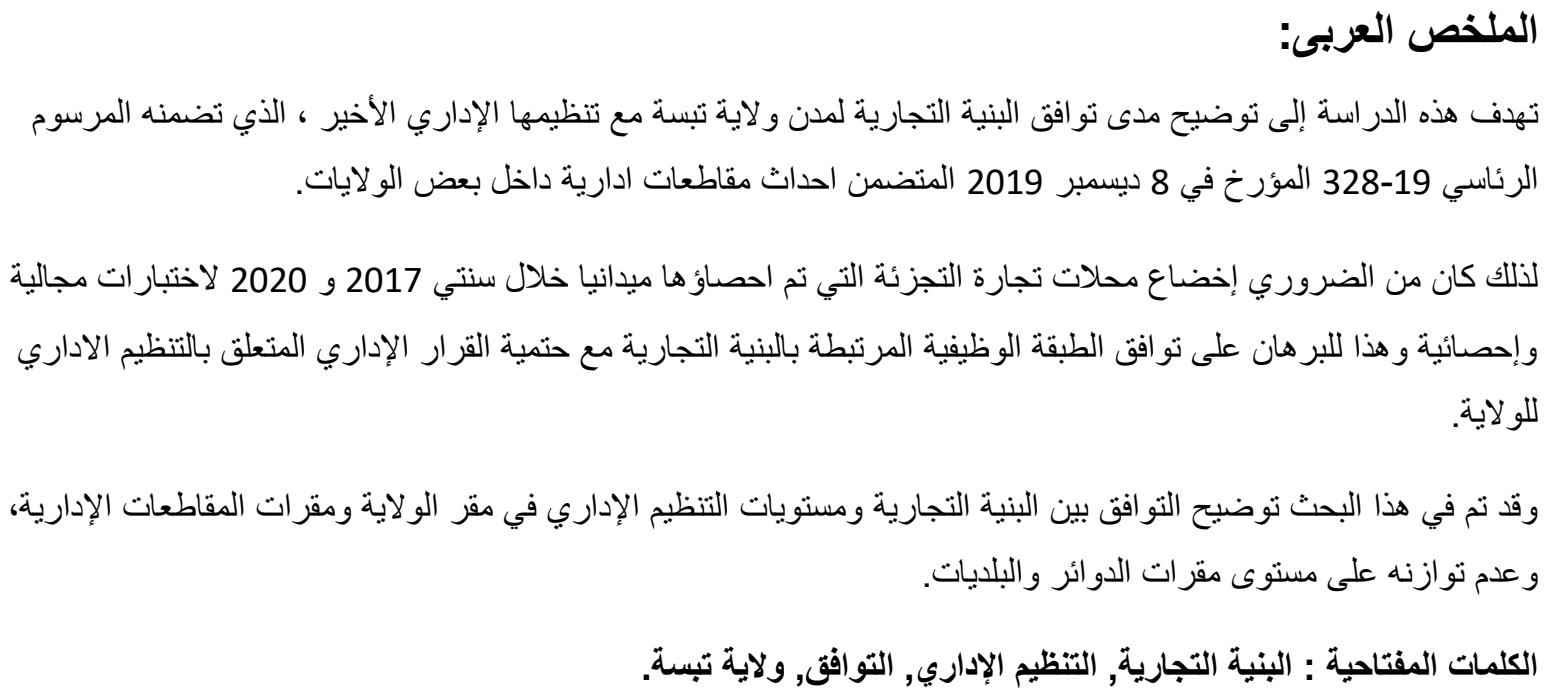

\section{Introduction}

The new administrative organization included in the Presidential Decree 19-328 dated in December 8, 2019, which completes the Presidential Decree 15-140 dated in May 27, 2015 which includes the creation of administrative districts within some states [1], is one of the most important topics for the citizens of Tébessa, like. Most of them believe that this administrative division came as a result of an administrative decision that did not take into account the homogeneity of the administrative entity with the functional one [2].

Since the state domain is in continuous interaction due to the visible and invisible relations resulting from a set of the layers forming its systems represented in the integrated, coordinated and influential activities and functions between them [3].

It will rely on the commercial structure related to partial commercial stores in testing the space functional compatibility with administration obligation, as the commercial activity is the most important based economic appliance structured for the space and a key engine for relationships interior a basic factor in its organization [4].

So, the spotlight was placed on the border state of the Tebessa positioned in the extreme highlands of eastern Algeria, and its population reach's at end of 2020, 794528 population[5]. and the number of commercial stores in it was 30319 commercial store categories in 136 types.

This qualifies it to benefit from creating a new administration rank presented in administration districts Bir-El Ater, Cheria, Ouenza in addition to the city of Tébessa Capital of the state.

Following this logic, the following question are asked:

How well match the functional structure related to commercial stores with organizational structure coming from the last administration decision in the state of Tébessa? 


\section{COMPATIBILITY BETWEEN SPATIAL FUNCTIONALITIES RELATED TO TRADE WITH THE LAST \\ ADMINISTRATIVE ORGANIZATION OF TÉBESSA STATE-ALGERIA}

\section{Material and Research Methods}

And for treatment of study subject problematic was followed a specific methodology presented in relying on personalization style and site data analyze which was collected in 2017 and 2020, with multiscale approach and this all levels followings:

A- Level One: approximate, through the division of each city into urban sectors to vacillate the operation of the site sweeping and this based on districts cards and master plan for layout and urban planning especially for important cities from the number commercial stores.

B- Level Two: local, is studied by calculating the number of all types of stores at the level of each city.

C-Level Three: territorial, allows to know the real weight of the commercial stores in each city at the level of the state.

The method used in this research is descriptive, quantitative, and comparative which confirms that the variances related a commercial stores compatibility and Rank imbalance in each city according last administration organization of the state.

Fom the foregoing, it is possible to know the reasons for the spatial dysfunctional based on the commercial structure with its new regional organization.

Thus, the research method embodied the following steps:

\section{A- The Step of the Field}

In order to be able to achieve the desired results through this research, necessary information, data, and statistics related to the topic were collected. Therefore, data collection was carried out at the first time by the administrative departments, and then many field investigations were carried out to complete all the data.

\section{Collecting Statistical Data at The Administrative Departments}

It consists of communicating with various administrative and technical services in order to review the official documents that would enrich the subject, while organizing meetings with officials and specialists from certain administrations such as:

- National statistics office

- Department of programming and budget monitoring.

- Technical services of the municipalities and departments of the state of Tebessa.

- Direction of urbanism, architecture, and construction of the State of Tebessa and the sub-divisions of the departments.

- Direction of Commerce of the state of Tebessa and its sub-divisions,

- Service of Commercial Register of the state of Tebessa.

Despite the multiplicity of administrative services, it was not possible to collect all the data necessary for the research, even if some of them are available; they are either incomplete or incompatible with the various documents obtained from the various services.

\section{Collection of Statistical Field Data}

JAUES, 17, 62, 2022 


\section{COMPATIBILITY BETWEEN SPATIAL FUNCTIONALITIES RELATED TO TRADE WITH THE LAST ADMINISTRATIVE ORGANIZATION OF TÉBESSA STATE-ALGERIA}

It is considered as the most important step in the preparation of the research because it is linked to counting the partial commercial stores in the towns of Tébessa, i.e., the towns with a population of more than 5000 inhabitants. [6]. according to their presence in the field for two full years (2017-2020).

\section{B- The Data Analysis Step}

There are several ways to evaluate the spatial distribution pattern of business activities, and they range from simple descriptive visual analysis to geographical analysis. This is related to the nature of the data used to measure this phenomenon and to clarify its role in managing the urban network of cities [7].

Accordingly ,after collecting the data and information related to the topic of the research, they were classified and analyzed in order to present the results in several forms: matrices, tables, and graphs to support the discussion and results, which helps in explaining the phenomena that the research seeks to analyze and link its elements together.

Consequently, the statistical laws (the mean, the standard deviation, the correlation coefficient...) were used and the thematic analysis program (MapInfo PROFESSIONAL 8.0) [8]. The obtained data was then processed using the following equations:

\section{A- Indicator of Commercial Concentration}

This consists of the scarcity logic of commercial stores instead of the global ones and this shows the actual real weight for the business activity in Tébessa city which offers a urban system that allows hierarchy for centers of commercial concentration [9].

And for its calculation it must follow the arithmetic calculation following [10]:

$$
D c=\sum(S k \times C c)
$$

$D c$ : Indicator Davies for each city, Sk: Scarcity coefficient commercial stores for Kind of shops in each city, $C c$ : number of commercial stores in each city, Such as:

$$
S k=\frac{1}{C K c}
$$

$C k c$ : number of commercial stores for Kind of shops in each city.

\section{B- Indicator of Commercial Centrality}

The Commerce Centrality Indicator is based on the number of residents, which is the engine of business activity, so the Bennison Indicator relates between the Davies Indicator and the number of residents in each city. However, the calculation of the Bennison Indicator is very complex [11], and in order to reach it, a calculation must be performed [12]: 


$$
C t r=\frac{D c \times P s}{P c}
$$

Ctr: centrality for Kind of shops in each city, Ps: Population of state, Pc: Population of city.

$$
\operatorname{Ctr} A=D x C t r
$$

CtrA: absolute centrality for kind of shops in each city. For that it requires

The absolute concentration of a particular city, through relations (3) and (4) produces the following relationship (5).

$$
\begin{aligned}
& \operatorname{Ctr} A=\frac{D^{2} \times P s}{P c} \\
& \operatorname{Ctr} R=\frac{\operatorname{Ctr} A}{\operatorname{Ctr} A s} .
\end{aligned}
$$

CtrR : relative centrality for Kind of shops in each city, CtrAs: absolute centrality for Kind of shops in state.

$$
B=\sum \operatorname{CtrR}
$$

$B$ :Bennison Indicator, $\sum C t r R$ : Sum of relative centrality for various commercial activities in the city.

\section{RESULTS}

\subsection{Overview of the Tebessa state}

The state of Tebessa is located in the far east of the highlands on the Algerian-Tunisian border. It is bounded to the north by the state of Souk Ahras, to the south by the state of El Oued, to the east by Tunisia, and to the west by the wilaya of Oum El Bouaghi and the wilaya of Khenchela [13].

It covers an area of $13,878 \mathrm{~km} 2$ and its population, according to the 2008 census, is 723,393 inhabitants [14]. It includes 4 districts and 28 municipalities and 12 departments.

However, it was a district belonging to the state of Annaba [15], yet, in 1974 it rose to the ranks of a state comprising five districts and eighteen municipalities [16]. It was also included in the administrative division of $1985 \mathrm{AD}$, which aims to search for the consistency of the regional base with the objectives 
of the country's development and the promotion of the population by reducing the area of its state region after the upgrading of the neighboring cities of Khenchela and Souk Ahras to states [17].

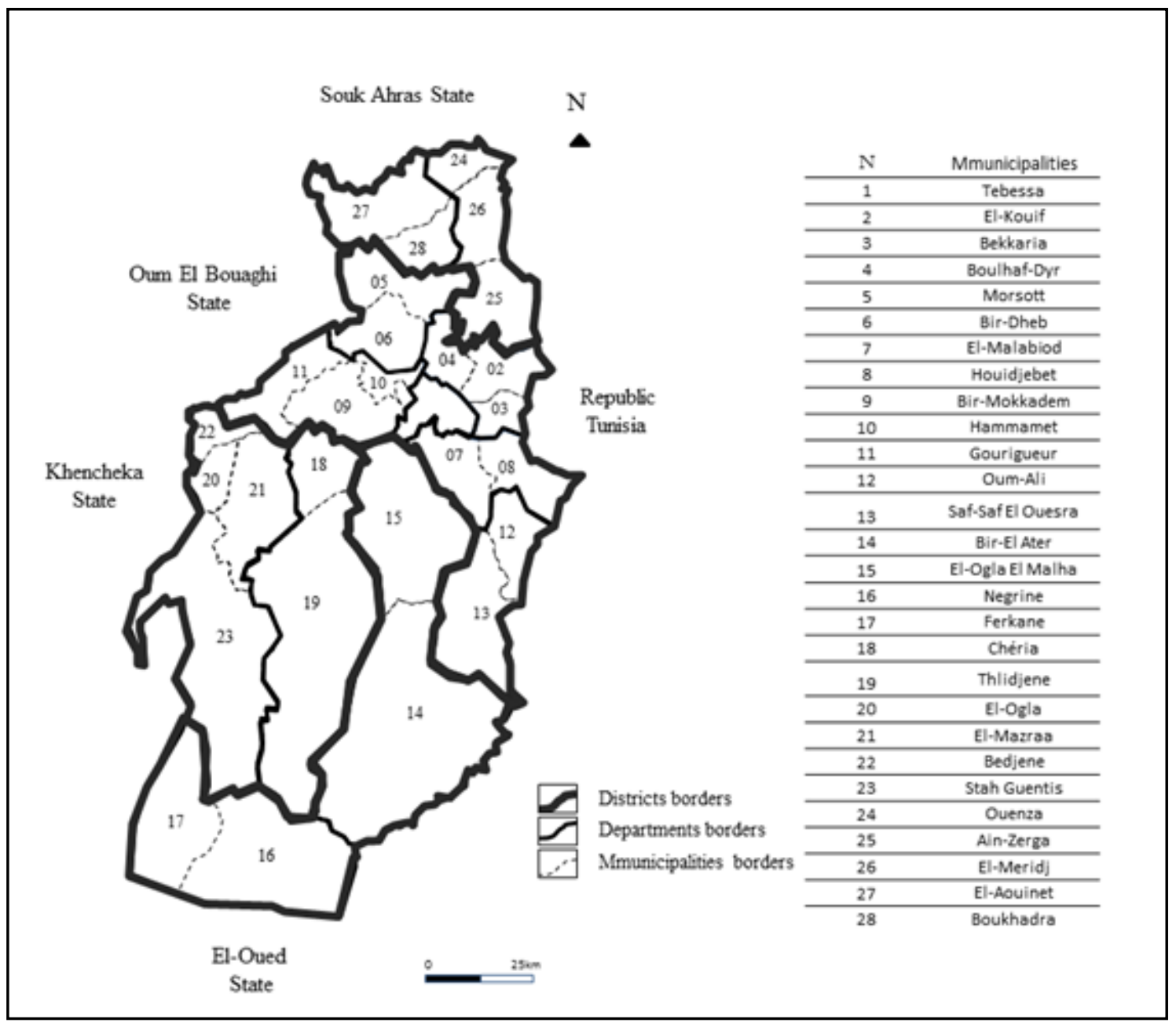

Figure 01: Administrative division of Tebessa state

\subsection{Number of shops according to field investigation}

The field survey of the various forms of shops in urban centers with a population of more than 5000 people in the state of Tebessa, estimated at 28 centers during the period between January 2017 and December 2020, enabled the counting of 30319 shops based on 136 types, where it occupies the city of Tebessa (state headquarters). ) ranked first with $39.01 \%$ of the total shops in the state, followed by the city of Bir-El Ater, Cheria, and Ouenza (the headquarters of administrative districts) with rates estimated, respectively, at $16.32 \%, 15.23 \%, 12.04 \%$ of the total shops in the state, and the city of Hammamet occupies, respectively. (Municipality headquarters) ranked sixth with $2.67 \%$ of the total shops in the state, as it is ahead of all departments headquarters, including the headquarters of the department to which it is affiliated regionally, except for the city of El-Aouinet (department headquarters), which is ranked first $2.92 \%$ of the total shops in the state. The city of Negrine and Oum 


\section{COMPATIBILITY BETWEEN SPATIAL FUNCTIONALITIES RELATED TO TRADE WITH THE LAST ADMINISTRATIVE ORGANIZATION OF TÉBESSA STATE-ALGERIA}

Ali (the headquarters of the departments) are late in the ranking, as they are ranked 15th and 19th with rates estimated at 0.55 and 0.30 of the total shops in the state, respectively.

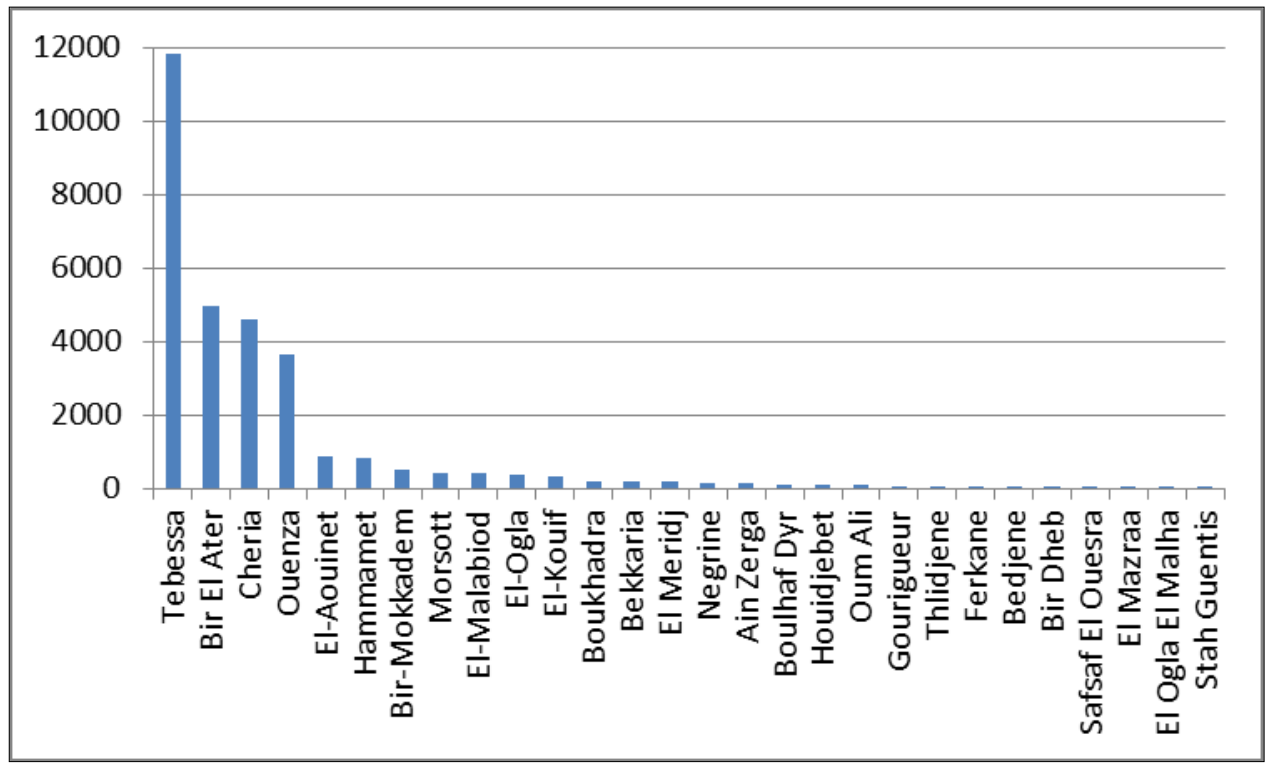

Figure 02: Number of shops according to field investigation in cities of state of Tebessa

source: Field investigation, 2017-2020.

\subsection{The relationship of the number of shops to the size of the population}

In order to know the relationship between the number of shops and the size of the population in the cities of Tebessa, the following graph was created, which shows:

The correlation coefficient was 0.98 , which is a high value and close to one (1), and this indicates the strength of the relationship. This means that the higher the population size, accompanied by an increase in the number of shops, thus serving the population with the best coverage.

The city of Tebessa (the headquarter of the state) appears close to the ideal line, which is explained by the strong relationship between the number of its residents and the number of shops in it. The city is different from other cities.

- The city of Bir El-Ater, Cheria, and Ouenza (headquarters of administrates districts) appear in a prominent group and move higher than the rest of the other cities (headquarters of departments and municipalities), and this is explained by its secondary occupation in terms of commercial centralization compared to the rest of the cities. As for its location in relation to the ideal line, it is very close to it in the upper part, and this indicates that the concentration of shops in these towns does not only serve its inhabitants, but extends its service to the rest of the towns, especially the neighbors.

- As for the rest of the cities, they are concentrated in a group which is located below the ideal line, because they suffer from a lack of shops, which forces their inhabitants to rely on the shops of neighboring municipalities, in particular in terms of business activities that do not exist for them. 


\section{COMPATIBILITY BETWEEN SPATIAL FUNCTIONALITIES RELATED TO TRADE WITH THE LAST ADMINISTRATIVE ORGANIZATION OF TÉBESSA STATE-ALGERIA}

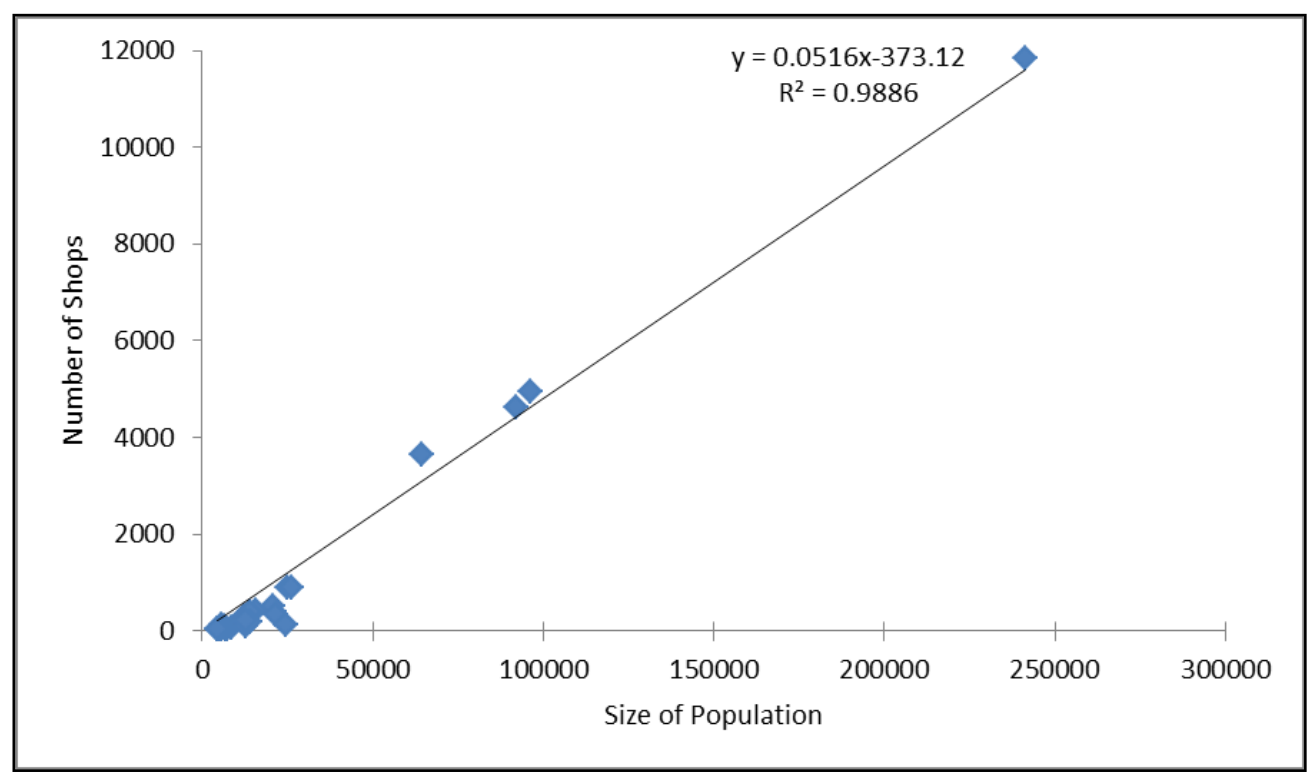

Figure 03: The relationship of the number of shops to the size of the population Source: Field investigation, 2017-2020.

\subsection{Classification of cities of Tebessa state according to Davies and Bennison indicator}

After exploiting the data from the field survey by applying a set of mathematical relationships, the following table was obtained related to the indicators of Benson and Davis has been produced relating to the classification of the cities of the state of Tebessa, according to the indicators of centrality and commercial concentration, and with using the statistical method adopted for the calculation of the correlation coefficient reached between them in the case of the study with 0.99 , which is a very close value from 1 , which indicates the existence of a positive relation between them. 

ADMINISTRATIVE ORGANIZATION OF TÉBESSA STATE-ALGERIA

Table 1: Classification of cities of Tebessa state according to Davies and Bennison indicator

\begin{tabular}{|c|c|c|}
\hline TEBESSA & 58,3336 & 58,3909 \\
\hline BIR-EL ATER & 23,3699 & 23,8364 \\
\hline CHERIA & 20,6463 & 19,7651 \\
\hline OUENZA & 15,7298 & 16,9321 \\
\hline EL-AOUINET & 4,6967 & 4,0559 \\
\hline HAMMAMET & 3,4851 & 2,8765 \\
\hline BIR-MOKKADEM & 1,8561 & 1,5734 \\
\hline MORSOTT & 1,4868 & 0,7847 \\
\hline EL-MALABIOD & 1,4302 & 1,1662 \\
\hline EL-OGLA & 1,1211 & 0,6183 \\
\hline EL-KOUIF & 0,8611 & 0,2938 \\
\hline BEKKARIA & 0,445 & 0,1869 \\
\hline EL-MERIDJ & 0,4239 & 0,1585 \\
\hline BOUKHADRA & 0,402 & 0,1577 \\
\hline NEGRINE & 0,3996 & 0,3602 \\
\hline AIN-ZERGA & 0,2539 & 0,0366 \\
\hline OUM-ALI & 0,2241 & 0,6864 \\
\hline BOULHAF-DYR & 0,1998 & 0,1352 \\
\hline GOURIGUEUR & 0,1552 & 0,4491 \\
\hline HOUIDJEBET & 0,1438 & 0,0856 \\
\hline THLIDJENE & 0,0681 & 0,0120 \\
\hline FERKANE & 0,0662 & 0,0171 \\
\hline EL-MAZRAA & 0,0443 & 0,0187 \\
\hline BIR-DHEB & 0,0385 & 0,0111 \\
\hline BEDJENE & 0,0361 & 0,0112 \\
\hline SAF-SAF EL OUESRA & 0,0331 & 0,0097 \\
\hline EL-OGLA EL MALHA & 0,0261 & 0,0041 \\
\hline STAH GUENTIS & 0,0238 & 0,0109 \\
\hline
\end{tabular}




\section{COMPATIBILITY BETWEEN SPATIAL FUNCTIONALITIES RELATED TO TRADE WITH THE LAST ADMINISTRATIVE ORGANIZATION OF TÉBESSA STATE-ALGERIA}

Through this table, three categories can be identified as follows:

\subsubsection{First Category}

Includes the city of Tebessa, in which the value of the Davies indicator was estimated at 58,3336 and the Bennison indicator at 58,3909, which are high values compared to the rest values of other cities, and this indicates the correctness of its administrative rank as a city headquarters of the state.

\subsubsection{Second Category}

Includes each of the city of Bir-El Ater with a Davis indicator equal to 23,3699 and the Bennison indicator with 23,8364 as well as the city of Cheria with a Davies indicator estimated at 20,6463 and the Bennison indicator with 19,7651, the city of Ouenza with a Davis indicator equal to 15,7298 and the Bennison indicator estimated at 16,9321, which explains the gathering of These three cities, according to these indicators within this category, indicated the desirability of introducing the administrative rank represented in the administrative districts within the new organization for the year 2019 , from which the aforementioned cities benefited from them

\subsubsection{Third Category}

Includes the rest of the cities of the state where these percentages vary in terms of the consistency of the hierarchy between these two indicators that are close in value in different cities and the administrative rank, and this is evident through the presence of a clear imbalance in the hierarchy between the city of Hammamet (municipality headquarters) and the city Bir-Mokkadem (the headquarters of the department Followed administratively), as well as the hierarchy of the headquarters of the Negrine and Oum-Ali department, which came late compared to some municipals headquarters such as Hammamet, El-Meridj, Bekkaria, Boukhadra, Ain-Zerga and others

\section{Conclusion and the Discussion of Results}

In order to test the extent of the compatibility logical spatial function of Tebessa State with the Administrative decision related to the recent regional organization of Tebessa State, which it contains the presidential decree 19-328 dated in December 8, 2019 which complete the presidential decree 15140 dated in May 27, 2015 which contained creation of administrative districts in some state, it was based on the commercial structure of the urban system of Tebessa state, which was studied in under laws like the Davies Indicator, called the Commercial centrality Indicator, as well as the Bennison Indicator, which is based on the calculation of trade concentration, which is based on the Commercial centrality Indicator, as well as on the population, and that was studied it in the beginning research, And it turns out the following:

- The compatibility between the spatial functionality based on the commercial structure of the retail stores with the administrative rank of each of the cities of Tebessa as the capital of the state and the city of Bir-El Ater, Chéria, and Ouenza, which were promoted from the headquarters of the department to administrative districts. This rank was recently introduced within the territorial organization of the state of Tebessa.

- The regional organization must be reconsidered at the lower levels, in particular as regards the Hierarchy of the headquarters of the departments with the municipalities they administratively follow, in particular as regards the city of Hammamet affiliated territorially to the department of BirMokkadem or to the seat of some departments which are organized in lower ranks than some of the

JAUES, 17, 62, 2022 


\section{COMPATIBILITY BETWEEN SPATIAL FUNCTIONALITIES RELATED TO TRADE WITH THE LAST ADMINISTRATIVE ORGANIZATION OF TÉBESSA STATE-ALGERIA}

municipalities of other departments such as Negrine, which is considered a gateway to the desert and Oum-Ali on the Tunisian border.

Accordingly, it has become necessary, before carrying out any modification of the territorial organization of the country, to do the following

- Involve various urban actors, including the citizen, who is considered an essential element in decisionmaking.

- Establish an observatory at the state level and urban observatories at the city level that would be equipped with various real data related to all layers of the state, municipal and even neighborhoods functional system that would help study the functionality of the field at its various levels, especially focusing on geographic information systems.

- Review the legal arsenal related to urban and territorial planning with a universal and intersecting vision between the various actors and users in the field, all of this creates flexibility between the urban and territorial planning tools, which has become imperative for the relationship between them to be reciprocal and not superlative based on the principle of compatibility, not conformity, and then relying on it from a multidisciplinary team of experts in the territorial organization of the country.

\section{REFERENCES}

1. Official Journal of the Algerian People's Democratic Republic. (2019). Presidential Decree 19328 of December 8, 2019. $\mathrm{n}^{\circ} 76$.

2. Tartar N. (2013). The Urban Structure of the state of Biskra between polar attraction and the functionality of space. Magister memory. Department of Architecture, University of Mohamed Khaider, Biskra: Algeria. pp 21-22.

3. TOUMI F. (2016). The problem of the organization of commercial activities in urban space, case study of the city of Chéria. Magister memory. Urban Techniques Management Institute, University of Constantine 03, Constantine: Algeria, p A.

4. BAKHOUCHE Z. (2002). Commercial structures and urban dynamics. case study of the city of Biskra. State doctorate. Regional Planning Department, University of brother mantouri, Constantine: Algeria, p 67.

5. (DPBM) Department of programming and budget monitoring (2018). Monograph of Tebessa State: Algeria.

6. Official Journal of the Algerian People's Democratic Republic. (2006). Law 06-06 of February $20,2006 . \mathrm{n}^{\circ} 15$

7. Benghadban F. (2016). Analysis of the Spatial Distribution Correlation of the Commercial Activities in Major Algerian Citie (Empirical Study on the City of Annaba). Jordanian Journal of Social Sciences. Vol 9, NO 2, p 271.

8. TOUMI F .(2016). op. cit. p A-F.

9. BOUZAHZAH, F. (2015). Urban dynamics and new centrality, case of Biskra. Doctorate In Science. Regional Planning Department, University of brother mantouri, Constantine: Algeria, p 240.

10. AZBAOUI, S. (2005). The role of urban networks and roads in the organization of State of Oum El Bouaghi. Magister memory. Urban Planning Department, University of brother mantouri, Constantine: Algeria, pp 179-180.

11. BOUZAHZAH, F. (2015). op. cit. p 240. 


\section{COMPATIBILITY BETWEEN SPATIAL FUNCTIONALITIES RELATED TO TRADE WITH THE LAST ADMINISTRATIVE ORGANIZATION OF TÉBESSA STATE-ALGERIA}

12. FARHI, A (2000). New towns and towns of equilibrium, Case of Biskra and Batna. State Doctorate. Department of Architecture, University of brother mantouri, Constantine: Algeria, p 158.

13. MEDAREGNAROU BOUBIR, H (2015). The dimensions of the demo-functional transfers of the wilayal tebessi urban system: the role of development strategies in its hierarchical organization 1966-2008. State Doctorate. Department of Architecture, University of Mohamed Khaider, Biskra: Algeria. pp 115-116.

14. (DPBM) Department of programming and budget monitoring (2008). General Census of Population and Housing (Tebessa State) : Algeria.

15. Tartar N. (2019). Sustainability of Urban Planning for Residential Areas in Tebessa City Between Vision and Achieving Goals. The Algerian Review of Human Security. Vol 5, NO 1, p 759.

16. Official Journal of the Algerian People's Democratic Republic. (1974). Order 74-69 relating to the recasting of the Territorial Organization of the state, July 02, 1974. $\mathrm{n}^{\circ} 55$.

17. Official Journal of the Algerian People's Democratic Republic. (1984). Law 84-09 relating to the Territorial Organization of the Country, February 04, 1984. ${ }^{\circ} 06$. 